\title{
Effects of the cardiac myosin activator Omecamtiv-mecarbil on severe chronic aortic regurgitation in Wistar rats
}

\author{
Bachar El-Oumeiri ${ }^{*}$, Kathleen Mc Entee ${ }^{2}$, Filippo Annoni ${ }^{3}$, Antoine Herpain ${ }^{3}$, Frédéric Vanden Eynden ${ }^{1}$, \\ Pascal Jespers ${ }^{2}$, Guido Van Nooten ${ }^{1}$ and Philippe van de Borne ${ }^{4}$
}

\begin{abstract}
Background: Aortic regurgitation (AR) is a valvular disease that can lead to systolic heart failure. Treatment options besides cardiac surgery are limited and consequently severe AR is associated with higher mortality and morbidity when not operated. In this investigation, we examined the effects of a novel cardiac myosin activator, Omecamtiv-mecarbil (OM), in rats with chronic severe AR.

Methods: AR was created by retrograde puncture of the aortic valve leaflets in 20 adults Wistar rats. 12 animals survived the acute AR phase and were randomized 2 months thereafter into OM $(n=7)$ or placebo groups $(n=5)$. Two rats underwent a sham operation and served as controls. Equal volumes of OM or placebo $(\mathrm{NaCl} 0.9 \%)$ were perfused in the femoral vein by continuous infusion $(1.2 \mathrm{mg} / \mathrm{kg} / \mathrm{hour}$ ) during $30 \mathrm{~min}$. Doppler-echocardiography was performed before and at the end of the infusion periods.

Results: OM increased indices of global cardiac function (cardiac output, stroke volume), and increased systolic performance (fractional shortening, ejection fraction, left ventricular end systolic diameter) (all $p<0.05$ ). These effects concurred with decreases in indices of LV preload (left atrial size, left ventricular end diastolic diameter) as well in the aortic pre-ejection period / left ventricular ejection time ratio (all $p<0.05$ ). The severity score of the regurgitant AR jet did not change. Placebo infusion did not affect these parameters.
\end{abstract}

Conclusion: The cardiac myosin activator OM exerts favorable hemodynamic effects in rats with experimental chronic AR. Keywords: Omecamtiv-mecarbil, Aortic regurgitation, Doppler-echocardiography, Wistar rat, Left ventricle

\section{Background}

Aortic regurgitation (AR) is a valvular disease that affects men more than women, and whose incidence increases with age [1]. Severe AR is associated with higher morbidity and mortality compared to the general population [2]. Chronic AR secondary to rheumatic fever is a frequent condition in developing countries and in populations having no adequate access to health care [3]. Chronic severe AR imposes a combined left ventricular (LV) volume and pressure overload. Volume increase is a direct consequence of the regurgitant volume itself, while pressure overload results from increased parietal

\footnotetext{
* Correspondence: Bachar.El.Oumeiri@erasme.ulb.ac.be

'Department of Cardiac surgery, Erasme Hospital, ULB, 808 Lennik road, 1070, Brussels, Belgium

Full list of author information is available at the end of the article
}

stress and systolic hypertension [4]. AR is associated with a long asymptomatic period during which the LV progressively enlarges and hypertrophies in response to a chronic volume overload. The increased wall stress and LV volume/mass ratio can lead to impaired LV systolic function, clinical signs of heart failure and, finally, become irreversible and lethal [5]. So far, vasodilators are the only drugs indicated in asymptomatic AR, but their hemodynamic effects are inconsistent and their impact on clinical outcomes is largely uncertain [6,7]. Rats are convenient animals to evaluate the response of the LV to severe AR as they develop LV abnormalities in a relatively short period of time (weeks). This is in contrast to humans, who can tolerate this condition without apparent LV dysfunction for decades [8]. The rats develop progressive $\mathrm{LV}$ dilatation and eccentric 
hypertrophy, due to a chronic LV volume overload, as well as progressive irreversible LV systolic dysfunction, mimicking closely the evolution of the disease over a much larger time span in humans [9].

In chronic AR, indices of systolic function such as left ventricular ejection fraction (LVEF) are better prognostic indicators than indices of cardiac overload [2]. Moreover, markers of systolic function are useful for decision of a timely surgical valve replacement [10, 11]. Conventional medical treatment of congestive heart failure with altered ejection fraction is based on neuro-hormonal blockade, neuro-hormonal activation being considered responsible for aggravation of heart failure and loss of myocardial contractility [12]. Because of safety issues, conventional therapies that directly target cardiac contractility are sparsely used [13]. Heart failure (HF) remains a major public health problem worldwide. Existing drugs increase cardiac contractility indirectly through signaling cascades but are limited by their mechanism related adverse effects. To avoid this limitation Omecamtiv-mecarbil (OM) was developed. Omecamtiv-mecarbil, formerly called CK-1827452 (Cytokinetics Inc., San Francisco, CA, USA) is a novel drug which improves cardiac contractility by means of cardiac myosin activation. OM accelerated the transition of myosin from the weakly actin-bound to strongly actin-bound state measured by release of Hydrolazed Phosphate ( $\mathrm{Pi}$ ). OM appeared to shift the equilibrium towards myosin adenosine triphosphate (ATP) hydrolysis without affecting the rate of hydrolysis, in addition to accelerating the rate of $\mathrm{Pi}$ release. OM decreased the rate of Pi release when actin was removed. This decrease in actin-independent ATP hydrolysis potentially increases the overall energetic efficiency of the system by diminishing ATP use not associated with mechanical work [14]. Consequently, OM increases systolic ejection duration without changing the rate of left ventricular pressure development $[15,16]$.

In two different canine models of pacing-induced systolic heart failure (after myocardial infarction [15] and in the presence of left ventricular hypertrophy [15]), OM increased systolic wall thickness and fractional shortening (FS), leading to an improved global cardiac function and lowered heart rate (HR), while myocardial energetics and loading conditions did not change. Cardiac morphology alterations in tachycardia-induced cardiomyopathy include chamber dilatation and normal or reduced ventricular wall thickness, with little or no change in myocardial mass. These changes, together with myocardial energy depletion and impaired energy utilization, are reversible once HR normalizes [17].These characteristics differ completely from the chronic volume and pressure overload in severe AR, leading to LV dilatation and eccentric hypertrophy, an ultimately, to an irremediably compromised LV function. Favorable effects of $\mathrm{OM}$ in experimental pacing-induced cardiomyopathy may thus not apply to chronic severe AR. Consequently, the goal of the present study was to test the hypothesis that cardiac myosin activation with OM improved left ventricular function in a rat-model of chronic severe aortic regurgitation. The expanded goal of this study was to determine if OM affected AR severity.

\section{Methods \\ Animals}

Experiments were approved by the Institutional Animal Care and Use Committee of the Free University of Brussels. Studies were conducted in accordance with the Guide for the Care and Use of Laboratory Animals published by the National Institutes of Health (NIH Publication No. 85-23, revised 1996). Twenty-four male adult Wistar rats (401 $\pm 90 \mathrm{~g}$ body weight) were randomized to a sham intervention $(n=4)$ or to AR creation $(n=20)$. Rats that survived the acute phase $(n=12)$ were randomized into an OM group $(n=7)$ or a placebo group $(n=5)$. The 4 rats (two in the OM group and two in the placebo group) who underwent a sham operation served as controls for the effect of time and measurement repetition on the parameters investigated in the study.

\section{Interventions}

AR was created by retrograde puncture of the aortic valve leaflets under general anesthesia, as previously described [18]. Briefly, the animals were anesthetized with an intraperitoneal injection of $75 \mathrm{mg} / \mathrm{kg}$ of ketamine and $0.25 \mathrm{mg} / \mathrm{kg}$ of medetomidine. HR and rhythm were monitored via limb leads throughout the procedure. The right internal carotid artery was surgically exposed. A fixed core wire guide .025" (COOK incorporated, IN, 47404, USA) was advanced toward the aortic valve in a retrograde manner to tear valve leaflets and induce AR. The following echocardiographic criteria with popping sensation at the time of surgery were used to include animals in the study: a jet extent above $30 \%$ of the length of the LV and color-Doppler ratio of regurgitant jet width to LV outflow tract diameter above 50\% [19]. The 2 sham-operated animals had their right carotid artery cannulated without puncturing the aortic valve. Animals were closely observed during the first hours and days after surgery for any sign of respiratory distress suggestive of acute heart failure.

\section{Measurements}

Transthoracic 2D, M-mode and Doppler echocardiography were performed under general anesthesia with an ultrasound unit (Vivid-7, GE Healthcare, US) equipped with a $10 \mathrm{Mhz}$ surgical transducer. Rats were placed in the right and left lateral recumbent positions and their 
electrocardiogram was monitored via limb leads throughout the procedure. All measurements were made according to the recommendations of the American Society of Echocardiography currently applied to humans [19]. Standard right parasternal (long and short axis) and left apical parasternal views were used for data acquisition. Left atrial size was assessed in right parasternal short axis at the level of the aorta. Diastolic (d) and systolic (s), septal wall thickness (SWT), posterior wall thickness (PWT) and LV diameters (LVEDD, LVESD) were measured in M-mode from a LV short axis view at the level of chordae tendinae and fractional shortening (FS) was calculated. Ejection fraction (EF) were derived using the Teicholz formula. Left ventricle mass was calculated using the American Society of Echocardiography recommended formula: LV mass $=0.8 \times\{1.04$ [(LVEDD + PWTd + SWTd $\left.\left.)^{3}-(\text { LVEDD })^{3}\right]\right\}+0.6$ g. Aortic diameter was measured from the right long axis parasternal view. Aortic flow was measured from the left apical view to calculate forward stroke volume (SV) and cardiac output and to measure pre-ejection period (PEP: delay from Q wave of QRS to aortic opening, ms), LV ejection time (LVET: interval from beginning to termination of aortic flow, ms), and inter-beat interval (RR). Systolic time was determined as PEP + LVET (ms). Diastolic time (ms) consists in RR interval (ms) - systolic time (ms). PEP/ LVET ratio was also calculated. PEP/LVET is a more useful index of overall LV performance [20]. This ratio is better correlated with other LV performance measurements than either PEP or LVET, and is considered independent of HR [21]. Severity of the regurgitant aortic jet was subjectively graded (1 to 4 ).

\section{Experimental design}

Doppler-echocardiography was performed before AR creation, during surgery to confirm the presence and the severity of $\mathrm{AR}$, and 2 months thereafter, both before and after $\mathrm{OM}(1.2 \mathrm{mg} / \mathrm{kg} / \mathrm{hour})$ or placebo $(\mathrm{NaCl} 0.9 \%)$ infusion for $30 \mathrm{~min}$, by means of a femoral vein perfusion. All animals received equal volumes $(12 \mathrm{ml} / \mathrm{kg})$ of placebo or OM. This achieved plasma concentration of nearly $400 \mathrm{ng}$ of $\mathrm{OM} / \mathrm{ml}$ in a previous study [22]. Doppler-Echocardiography was performed after $30 \mathrm{~min}$ infusion. All animals remained alive during these experimental sessions which could thus be completed in 5 rats with placebo and 7 rats with OM.

\section{Statistical analysis}

Results are expressed as means \pm SD. A 2-factor ANOVA for repeated measures followed by post-hoc Bonferroni corrections for multiple comparisons was used to assess the effects of OM versus placebo, and any interaction between them, after 2 months of AR on the 16 animals. All other statistical analysis consisted of paired-t tests between variables. Significance was set at a $p$ value less than 0.05. (SPSS 23.0, IBM, Chicago, Ill, USA).

\section{Results}

AR and LV measurements (Fig. 1)

AR was achieved in all 20 animals and confirmed by the presence of a regurgitant jet quantified as severe in all animals. Eight animals died of congestive heart failure within 2 months and were not included in the final analysis. After 2 months AR (graduated from 0 to 4) was achieved at $3.67 \pm 0.44$, and echocardiographic signs of volume overload and eccentric hypertrophy were present with increased left atrial diameter, LVEDD, LVEDV and LV mass ( $n=12$, all $p<0.05$, paired $\mathrm{t}$ tests). Load dependent indices of LV systolic function (FS and $\mathrm{EF}$ ) were unchanged but LVESD were increased. SV and cardiac output were decreased $(n=12$, both $p<0.01$, paired $\mathrm{t}$ tests). As expected, no AR was detected in sham operated rats $(n=4)$ with no modifications of LV function or dimension in the placebo group while only FS and EF increased after injection of OM $(p=0.011$ and $p=0.032$, respectively) (Table 1 ).

\section{Effects of placebo in rats with AR (Table 2)}

Before infusion, there was no difference in echocardiographic results between the 2 groups (placebo versus $\mathrm{OM}) . \mathrm{NaCl}$ infusion affected none of the echocardiographic parameters of global and systolic cardiac function neither the indices of LV preload $(n=5, p>0.06$, paired $t$ tests).

\section{Effects of OM in rats with AR (Table 3)}

$\mathrm{OM}$ increased indices of global cardiac function (SV, cardiac output), decreased HR and increased systolic performance (FS, EF) $(n=7$, all $p<0.05$, paired t tests). These effects concurred with decreases in measures of LV preload (Left atrial diameter, LVEDD), and a decreased PEP/LVET ratio $(n=7$, all $p<0.05$, paired $\mathrm{t}$ tests). OM did not affect the severity score of the AR jet.

\section{Effects of OM versus placebo after 2 months of AR (Table 4)}

Two-way ANOVA with Bonferroni corrections for multiple comparisons after 2 months of AR were done on the effects of placebo versus OM. Only FS and EF increased after OM as compared to placebo ( $p=0.014$ and $p=0.012$, respectively) (Fig. 2). None of the other hemodynamic changes investigated in this study achieved the level of significance in this analysis (none illustrated). 


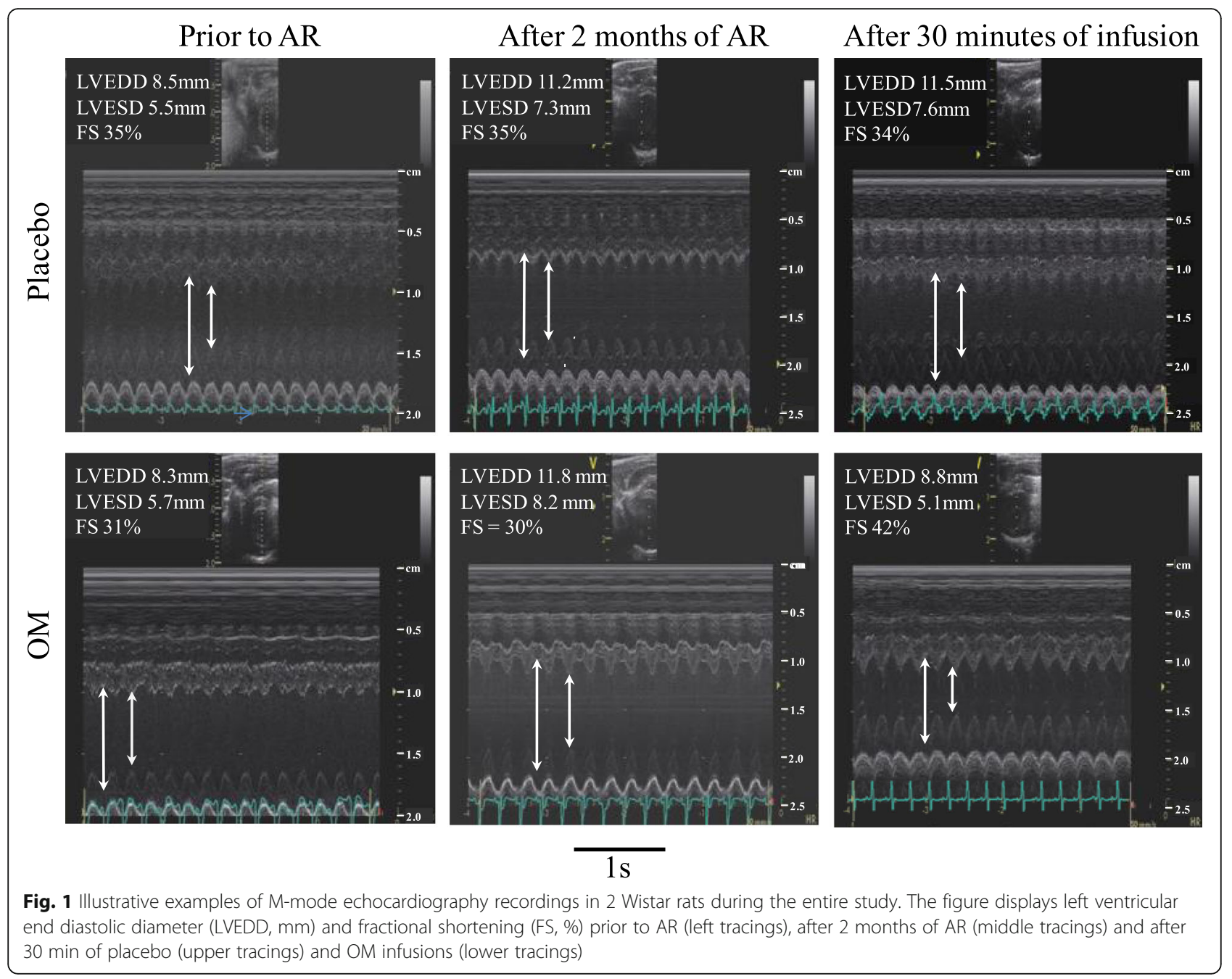

\section{Discussion}

We investigated the effect of the cardiac myosin activator $\mathrm{OM}$ on severe chronic $\mathrm{AR}$ in an experimental ratmodel. The main findings of our study are that OM decreases volume overload induced by chronic AR. As OM lessened LVEDD and LVESD and increased SWTs, we can assume that OM markedly decreased LV wall stress in the presence of a severe chronic AR. We are not aware of a previous similar placebo-controlled study.

\section{Effects of OM on cardiac function}

The central hemodynamic feature of chronic AR is a combined volume and pressure overload of the $\operatorname{LV}[4,23]$. The LV responds to volume overload with a series of compensatory mechanisms, including a LV dilatation, an increase in chamber compliance and a combination of eccentric and concentric hypertrophy. The ejection phase indexes of LV systolic function at rest remain normal. However, an enlarged chamber size with the associated increase in wall stress also results in a stimulus for further hypertrophy
[24]. Despite the small number $(n=4)$ of sham animals, OM increase EF and FS in sham OM group $(n=2)$.

In our study OM decreased volume overload induced by AR during the whole cardiac cycle, by lowering LVEDD. Moreover, by decreasing LVEDD and LVESD and increasing SWTs, OM decreased wall stress in AR. This is of importance, since an increased wall stress may lead to overt LV systolic dysfunction [25]. Improving cardiac systolic function with a cardiac myosin activator could be favorable to ventricular remodeling [26].

In our study OM decreased the PEP/LVET ratio, a reliable index of LV performance. Acute reduction in afterload in patients with congestive heart failure improves LV systolic performance and decreases the PEP/LVET ratio, while an increase in preload will shorten PEP, prolong LVET and decrease PEP/LVET [27]. We found that despite preload reduction by OM, PEP was shortened and cardiac performance improved. This mechanism could explained the increase in stroke volume [28]. An improvement in cardiac function after infusion of $\mathrm{OM}$ in mongrel dogs, where heart failure was achieved by rapid ventricular 
Table 1 Two-way ANOVA statistics with Bonferroni correction at base (T1), before injection (T2) and after injection (T3) for all sham animals $(n=4)$

\begin{tabular}{|c|c|c|c|c|c|}
\hline & $\mathrm{T} 1$ & $\mathrm{~T} 2$ & $p$ & T3 & $p$ \\
\hline Heart Rate (beats/min) & $258 \pm 11$ & $270 \pm 7$ & 0,756 & $193 \pm 15$ & 0,251 \\
\hline Left Atrium (mm) & $4.6 \pm 0.2$ & $6.2 \pm 0.3$ & 0,872 & $5.5 \pm 0.2$ & 0,118 \\
\hline LVEDD (mm) & $7.9 \pm 0.5$ & $11.1 \pm 0.4$ & 0,938 & $10.1 \pm 0.5$ & 0,209 \\
\hline LVESD (mm) & $5.5 \pm 0.4$ & $7.6 \pm 0.3$ & 0,736 & $6.1 \pm 0.4$ & 0,072 \\
\hline FS (\%) & $31.5 \pm 1.4$ & $30.5 \pm 1.0$ & 0,937 & $35.4 \pm 1.5$ & 0,011 \\
\hline EF (\%) & $64.1 \pm 2.0$ & $63.9 \pm 1.4$ & 0,630 & $68.8 \pm 2.5$ & 0,032 \\
\hline Stroke Volume (ml) & $0.34 \pm 0.03$ & $0.22 \pm 0.18$ & 0,448 & $0.30 \pm 0.04$ & 0,762 \\
\hline Cardiac Output (ml/min) & $79.5 \pm 9.3$ & $52.0 \pm 4.5$ & 0,890 & $61.6 \pm 8.6$ & 0,393 \\
\hline SWTs (mm) & $2.1 \pm 0.1$ & $2.3 \pm 0.2$ & 0,671 & $2.7 \pm 0.2$ & 0,457 \\
\hline SWTd (mm) & $1.4 \pm 0.1$ & $1.7 \pm 0.2$ & 0,971 & $2.1 \pm 0.2$ & 0,092 \\
\hline Systolic time (ms) & $126 \pm 3.7$ & $134 \pm 2.6$ & 0,245 & $135 \pm 2.6$ & 0,153 \\
\hline Diastolic time (ms) & $139 \pm 8.4$ & $135 \pm 8.3$ & 0,207 & $157 \pm 14.5$ & 0,138 \\
\hline PEP (ms) & $15.0 \pm 1.6$ & $25.4 \pm 1.3$ & 0,413 & $21.8 \pm 1.0$ & 0,308 \\
\hline LVET (ms) & $110 \pm 4.4$ & $109 \pm 2.8$ & 0,310 & $113 \pm 3.9$ & 0,268 \\
\hline PEP/LVET & $0.13+0.02$ & $0.23+0.02$ & 0,800 & $0.19+0.01$ & 0,968 \\
\hline Systolic time/RR & $0.48+0.02$ & $0.50+0.02$ & 0,344 & $0.47+0.02$ & 0,370 \\
\hline
\end{tabular}

Values are mean \pm SD. LVEDD Left ventricle end-diastolic diameter, LVEDV Left ventricle end-diastolic volume, LVESD Left ventricle end-systolic diameter, LVESD Left ventricle end-systolic volume, FS Fractional shortening, EF Ejection fraction, SV stroke volume, SWTs septal wall thickness at end-systole, SWTd septal wall thickness at end-diastole, PEP aortic pre-ejection period, LVET Left ventricular ejection time, RR inter-beat interval

Table 2 Two-tailed T-test before and after Placebo infusion on LV function after 2 months of AR in a rat model $(n=5)$

\begin{tabular}{llll}
\hline & Before infusion & After infusion & $p$-value \\
\hline Heart Rate (beats/min) & $249 \pm 18$ & $220 \pm 41$ & 0.437 \\
Left Atrium (mm) & $6.2 \pm 0.8$ & $5.8 \pm 1.1$ & 0.541 \\
LVEDD (mm) & $10.6 \pm 0.8$ & $12.24 \pm 1.07$ & 0.092 \\
LVESD (mm) & $7.5 \pm 0.6$ & $6.9 \pm 0.84$ & 0.341 \\
FS (\%) & $28.8 \pm 1.4$ & $29.6 \pm 5.2$ & 0.706 \\
EF (\%) & $60.8 \pm 1.8$ & $61.0 \pm 8.4$ & 0.968 \\
Stroke Volume (ml) & $0.24 \pm 0.04$ & $0.24+0.08$ & 0.890 \\
Cardiac Output (ml/min) & $60 \pm 8$ & $60 \pm 12$ & 0.369 \\
SWTs (mm) & $3.0 \pm 0.16$ & $2.9 \pm 0.47$ & 0.122 \\
SWTd (mm) & $1.6 \pm 0.17$ & $1.7 \pm 0.29$ & 0.281 \\
Systolic time (ms) & $136 \pm 5$ & $123 \pm 17$ & 0.340 \\
Diastolic time (ms) & $144 \pm 24$ & $173 \pm 41$ & 0.054 \\
PEP (ms) & $25.8 \pm 4.6$ & $21.2 \pm 6.2$ & 0.125 \\
LVET (ms) & $110 \pm 8$ & $102 \pm 14$ & 0.490 \\
PEP/LVET & $0.24 \pm 0.05$ & $0.20 \pm 0.05$ & 0.182 \\
Systolic time/RR & $0.49 \pm 0.05$ & $0.42 \pm 0.05$ & 0.047 \\
\hline Vaves armean \pm SD. Left &
\end{tabular}

Values are mean \pm SD. Left ventricle end-diastolic diameter; LVEDV: Left ventricle end-diastolic volume; LVESD: Left ventricle end-systolic diameter; LVESD: Left ventricle end-systolic volume; FS: Fractional shortening; EF: Ejection fraction; SV: stroke volume; SWTs: septal wall thickness at end-systole; SWTd: septal wall thickness at end-diastole PEP: aortic pre-ejection period; LVET: Left ventricular ejection time; RR: inter-beat interval
Table 3 Two-tailed T-test before and after OM infusion on LV function after 2 months of AR in a rat model $(n=7)$

\begin{tabular}{llll}
\hline & Before infusion & After infusion & $p$-value \\
\hline Heart Rate (beats/min) & $253 \pm 22$ & $207 \pm 35$ & 0.091 \\
Left Atrium (mm) & $6.2 \pm 0.8$ & $5.5 \pm 0.7$ & 0.037 \\
LVEDD (mm) & $11.6 \pm 1.09$ & $9.0 \pm 1.51$ & 0.003 \\
LVESD (mm) & $7.8 \pm 0.91$ & $5.4 \pm 1.30$ & 0.009 \\
FS (\%) & $32.1 \pm 3.4$ & $41.1 \pm 5.3$ & 0.004 \\
EF (\%) & $65.0 \pm 4.7$ & $76.6 \pm 5.8$ & 0.002 \\
Stroke Volume (ml) & $0.19 \pm 0.06$ & $0.36+0.11$ & 0.011 \\
Cardiac Output (ml/min) & $44 \pm 16$ & $76 \pm 14$ & 0.027 \\
SWTs (mm) & $2.67 \pm 0.48$ & $3.33 \pm 0.51$ & 0.390 \\
SWTd (mm) & $1.6 \pm 0.17$ & $2.4 \pm 0.39$ & 0.274 \\
Systolic time (ms) & $133 \pm 7$ & $147 \pm 8$ & 0.003 \\
Diastolic time (ms) & $127 \pm 16$ & $141 \pm 33$ & 0.384 \\
PEP (ms) & $25.0 \pm 2.3$ & $22.4 \pm 1.8$ & 0.042 \\
LVET (ms) & $108 \pm 6$ & $125 \pm 9$ & 0.002 \\
PEP/LVET & $0.23 \pm 0.02$ & $0.18 \pm 0.02$ & 0.007 \\
Systolic time/RR & $0.51 \pm 0.04$ & $0.52 \pm 0.06$ & 0.735 \\
\hline Values are men & &
\end{tabular}

Values are mean $\pm S D$. $L V E D D$ Left ventricle end-diastolic diameter,

LVEDV Left ventricle end-diastolic volume, LVESD Left ventricle end-systolic diameter, LVESD Left ventricle end-systolic volume, FS Fractional shortening, EF Ejection fraction, SV stroke volume, SWTs septal wall thickness at end-systole, SWTd septal wall thickness at end-diastole, PEP aortic pre-ejection period, LVET Left ventricular ejection time, $R R$ inter-beat interval 
Table 4 Two-way ANOVA statistics with Bonferroni correction at base (T1), before injection (T2) and after injection (T3) for all animals $(n=12)$

\begin{tabular}{|c|c|c|c|c|c|}
\hline & $\mathrm{T} 1$ & $\mathrm{~T} 2$ & $\mathrm{p}$ & T3 & $p$ \\
\hline Heart Rate (beats/min) & $226 \pm 23$ & $228 \pm 21$ & 0.890 & $208 \pm 28$ & 0.113 \\
\hline Left Atrium (mm) & $4.6 \pm 0.2$ & $6.2 \pm 0.3$ & 0.966 & $5.5 \pm 0.2$ & 0.277 \\
\hline LVEDD (mm) & $7.9 \pm 0.5$ & $11.1 \pm 0.4$ & 0.235 & $10.1 \pm 0.5$ & 0.066 \\
\hline $\operatorname{LVESD}(\mathrm{mm})$ & $5.5 \pm 0.4$ & $7.6 \pm 0.3$ & 0.871 & $6.1 \pm 0.4$ & 0.092 \\
\hline FS (\%) & $31.5 \pm 1.4$ & $30.5 \pm 1.0$ & 0.144 & $35.4 \pm 1.5$ & 0.014 \\
\hline $\mathrm{EF}(\%)$ & $64.1 \pm 2.0$ & $63.9 \pm 1.4$ & 0.173 & $68.8 \pm 2.5$ & 0.012 \\
\hline Stroke Volume (ml) & $0.34 \pm 0.03$ & $0.22 \pm 0.18$ & 0.129 & $0.30 \pm 0.04$ & 0.135 \\
\hline Cardiac Output (ml/min) & $79.5 \pm 9.3$ & $52.0 \pm 4.5$ & 0.098 & $61.6 \pm 8.6$ & 0.203 \\
\hline SWTs (mm) & $2.1 \pm 0.1$ & $2.3 \pm 0.2$ & 0.597 & $2.7 \pm 0.2$ & 0.652 \\
\hline $\mathrm{SWTd}(\mathrm{mm})$ & $1.4 \pm 0.1$ & $1.7 \pm 0.2$ & 0.439 & $2.1 \pm 0.2$ & 0.040 \\
\hline Systolic time (ms) & $126 \pm 3.7$ & $134 \pm 2.6$ & 0.626 & $135 \pm 2.6$ & 0.293 \\
\hline Diastolic time (ms) & $139 \pm 8.4$ & $135 \pm 8.3$ & 0.341 & $157 \pm 14.5$ & 0.293 \\
\hline PEP (ms) & $15.0 \pm 1.6$ & $25.4 \pm 1.3$ & 0.771 & $21.8 \pm 1.0$ & 0.577 \\
\hline LVET (ms) & $110 \pm 4.4$ & $109 \pm 2.8$ & 0.752 & $113 \pm 3.9$ & 0.180 \\
\hline PEP/LVET & $0.13+0.02$ & $0.23+0.02$ & 0.811 & $0.19+0.01$ & 0.378 \\
\hline Systolic time/RR & $0.48+0.02$ & $0.50+0.02$ & 0.567 & $0.47+0.02$ & 0.063 \\
\hline
\end{tabular}

Values are mean \pm SD. LVEDD Left ventricle end-diastolic diameter, LVEDV Left ventricle end-diastolic volume, LVESD Left ventricle end-systolic diameter, $L V E S D$ Left ventricle end-systolic volume, FS Fractional shortening, EF Ejection fraction, SV stroke volume, SWTs septal wall thickness at end-systole, SWTd septal wall thickness at end-diastole, PEP aortic pre-ejection period, LVET Left ventricular ejection time, RR inter-beat interval

pacing-induced energy depletion, has also been reported, because OM decreased LV end-diastolic pressure without affecting LV systolic pressure [15].

In contrast to our initial hypothesis, we found that OM did not affect the severity of the aortic leakage since the diastolic time-span remained unchanged, as a result of a reduction in HR. In mitigation, however, excessive prolongation the duration of systole might compromise myocardial blood flow, and thereby aggravate ischemia; even if studies with OM in patients with angina and ischemic cardiomyopathy seem reassuring in this regard [29]. This stands in contrast with inotropic drugs that enhance the risk of ischemia, arrhythmias and death. Hence forth those risks have limited their utility in treating acute and chronic heart failure [30].

Ketamine is a dissociative anesthetic agent that has cardiovascular effect resembling sympathetic nervous system stimulation,increase heart rate and cardiac output [31]. Medetomidine improves muscle relaxation, potentiates anesthetic action of ketamine and compensates the cardiac stimulating effect of ketamine by decreasing heart rate and cardiac output. Dexmedetomidine had no direct myocardial depressant effect in the rat heart in doses that are similar to those encountered under clinical conditions [32]. As animals were all anesthetized at the same regime, the decrease in heart rate observed in the OM group can be attributed to OM. However, we cannot predict if this bradycardic effect of $\mathrm{OM}$ had also been highlighted in conscious non-sedated animals.

\section{Possible differential effects of OM as compared to other inotropic agents in AR}

Dobutamine infusion, in patients with chronic aortic regurgitation and depressed LV ejection fraction, decreased LVEDD, LVEDV, LVESD and LVESV, while FS and EF improved [33]. In conscious dogs with heart failure, systemic and pulmonary systolic wall stress remained unchanged while HR, LV systolic pressure and LV dP/dt increased with Dobutamine [34]. Dobutamine also shortened LVET in healthy dogs [35]. On the opposite, in our study OM decreased HR and increased LVET, while others, in conscious dogs with systolic heart failure induced by rapid pacing, reported that $\mathrm{OM}$ did not affect LV dP/dt [15]. When a comparable concentration of OM than in our study was administrated in normal humans (400 ng/ml) [36], blood pressure did not change. Thus OM and Dobutamine tend to enhance LV contractility by increasing wall thickening and fractional shortening, but in the presence of unchanged afterload conditions with OM [37], while arterial pressure and total vascular resistance increase with Dobutamine.

Currently available inotropes Dobutamin, Dopamin, Milrinone and Levosimendan have demonstrated proarrhythmic effects linked to increased mortality that can limit their clinical utility [38]. Most inotropic agents modify calcium cellular homeostasis. This is important, as intracellular calcium plays an important role in myocardial oxygen demand [39]. The well-known and widely used sympathomimetic drug dobutamine increases calcium 


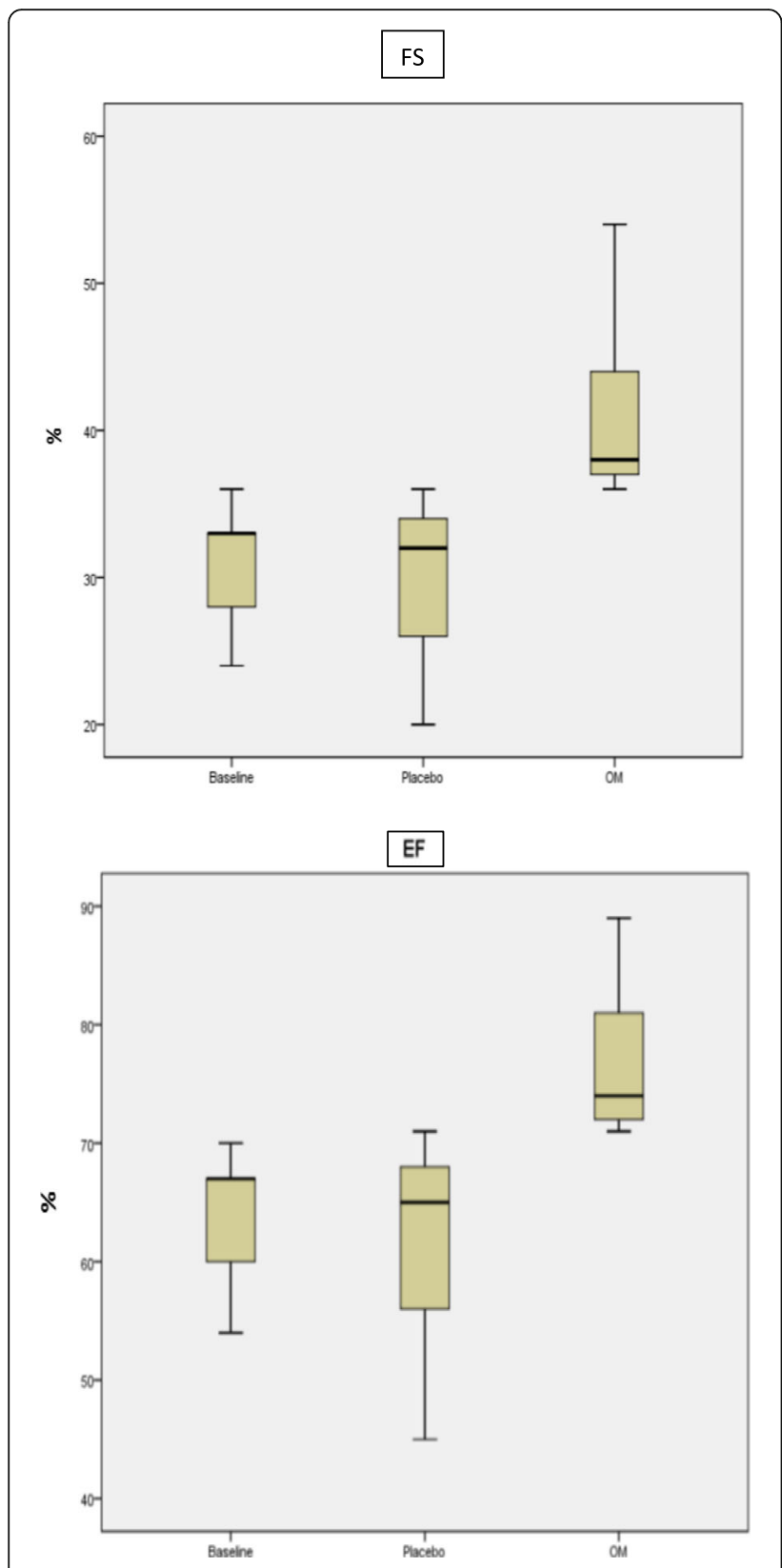

Fig. 2 Two-way ANOVA with Bonferroni corrections for multiple comparisons on the effects of OM versus placebo on FS ( $p=0.014)$ and EF ( $p=0.012)$ after 2 months of AR. Box and Whisker plots before infusion, and after infusion of OM vs. placebo (median: horizontal band within the box, box top and bottom: upper and lower first quartiles, top and bottom whiskers: highest and lowest quartiles; $n=12$ )

channels accessibility [40]. Other medications, such as levosimendan, enhance the sensitivity of troponin-c towards calcium, not at the expense of an increase in intracellular calcium concentration [22]. Levosimendan increases contractility by enhancing cross-bridge formation between actin and myosin $[22,41]$. The side effect of these increases in contractility is that they raise also myocardial oxygen consumption which is also pro arrhythmic. The molecules may also alter the expression of genes and promote the apoptosis of myocardial cells elicited by the increased intracellular calcium [39, 41]. OM inhibits non-actin dependent cardiac myosin adenosine triphosphate [16] and does not raise myocardial oxygen consumption [15]. A recent study in anesthetized animals suggested the opposite, namely that $\mathrm{OM}$ increased myocardial oxygen consumption [42], and however this was apparently undermined by methodological limitations [43]. These favorable characteristics of OM could prove useful in patients with AR.

\section{Effects of OM dose on the observed changes}

In our study we administrated $1.2 \mathrm{mg} / \mathrm{kg} / \mathrm{h}$ of OM during $30 \mathrm{~min}$. This was expected to raise plasma concentrations of OM to nearly $400 \mathrm{ng} / \mathrm{ml}$ [44]. In rats with heart failure induced by a ligation of the left coronary artery, infusion of OM resulted in comparable increases in FS than in our study, starting at plasma concentrations of approximately $200 \mathrm{ng} / \mathrm{ml} \mathrm{[44]}$. Administration of less than $0.48 \mathrm{mg} / \mathrm{kg} / \mathrm{h}$ of OM yield plasma levels $<160 \mathrm{ng} / \mathrm{ml}$, where no LV functional improvements where observed [36]. In healthy human improvements in EF began at a dose of $0.5 \mathrm{mg} / \mathrm{kg} / \mathrm{h}$, while improvements in FS, LVET and SV began at an infusion rate of $0.125 \mathrm{mg} / \mathrm{kg} / \mathrm{h}$ [36]. No change in orthostatic vital signs was noted in this study [45]. In patients with heart failure [45], LVET increased at OM concentrations $>100 \mathrm{ng} / \mathrm{ml}$, while SV and FS raised at plasma levels $>200 \mathrm{ng} / \mathrm{ml}$. EF increased only beginning concentrations $>300 \mathrm{ng} / \mathrm{ml}$. Supine and standing systolic blood pressure decreased at $>400$ and $>500 \mathrm{ng} /$ $\mathrm{ml}$, respectively. Last, in the ATOMIC-AHF study [46], patients with acute heart failure treated with OM disclosed a concentration-dependent reduction in $\mathrm{HR}$ at a concentration $>200 \mathrm{ng} / \mathrm{ml}$ while blood pressure increased at a concentration $>300 \mathrm{ng} / \mathrm{ml}$, as compared to placebo. There was also a concentration-related decrease in LVESD and increase in LVET. OM concentrations $>400 \mathrm{ng} / \mathrm{ml}$ achieved a better dyspnea response. Thus the dose administered in our study seems in the upper range of the concentrations where favorable hemodynamic modifications of $\mathrm{OM}$ are clear-cut, without being harmful. Adverse effects of OM consist in an excessive prolongation of systolic ejection time $>110 \mathrm{~ms}$ [36]. This was observed with supra therapeutic concentrations of OM $(\sim 1200 \mathrm{ng} / \mathrm{ml})$ which may induce myocardial ischemia by reducing the time during which diastolic coronary blood flow can occur [46]. A drug overdose in a patient with heart failure, with a predicted concentration of $1750 \mathrm{ng} / \mathrm{ml}$ at the time of infusion termination, resulted in chest pain, sweating, hypotension, and ECG changes suggestive of ischemia [45]. It is not known, 
however, that the angina symptoms, observed at supra-therapeutic concentrations of $\mathrm{OM}$, are related or not - to the presently recognized ryanodine receptors activating effect of OM [47].

\section{Study limitations}

The tested animal group was small because many rats did not recover from the acute AR procedure. Another striking limitation of our study resides in the fact that we could not achieve ventricular blood pressure measurement during the study. As such, our assessment of ventricular loading conditions remains incomplete. Several studies suggest however that systemic blood pressure is not affected at the OM concentrations we achieved in our study $[36,37]$. Our study did also not assess whether OM has dose-dependent hemodynamic effects in our model of AR. Lower doses of OM may still exert favorable hemodynamic effects, while even further reducing the risk of excessive prolongations in LVET. This will require additional studies. Moreover, as already discussed, a direct comparison of the effects of different inotropic agents in AR-related heart failure would also provide further insights in the differential hemodynamic effects of OM, as compared to other inotropic agents. Last, the effects of OM on animals who might otherwise not survive the decompensation period after an acute AR should be also studied. This is a very poorly tolerated condition in humans [48], which could benefit from further studies on the best hemodynamic support while awaiting cardiac surgery [48]. Last, the sham group in our study comprised only 2 animals in the OM group and 2 animals in the placebo group.

Another limitation of the study, the possible fistula with left atrium created during aortic valve leaflets puncture, this fistula can explain the decrease of stroke volume and cardiac output after the creation of the aortic regurgitation.

\section{Conclusion}

The present placebo-controlled study shows improvements in cardiac function after infusion of OM. Our investigations demonstrate these effects for the first time in the rat-model with chronic severe AR. We observed a decrease in volume overload and an increase in cardiac output and wall thickness. Moreover OM enhanced EF and FS, while coincidently lowering the $\mathrm{HR}$ and wall stress. On the other hand, OM did not affect the duration of diastole and the severity of AR.

\footnotetext{
Abbreviations

AR: Aortic regurgitation; ATP: Adenosin triphosphate; EF: Ejection fraction; FS: Fractional shortening; HR: Heart rate; LV: Left ventricle; LVEDD: Left ventricle end-diastolic diameter; LVESD: Left ventricle end-systolic diameter; LVET: Left ventricular ejection time; OM: Omecamtiv-mecarbil; PEP: Preejection period; Pi: Hydrolazed phosphate; RR: Inter-beat interval; SV: Stroke volume
}

\section{Funding}

This study was supported and funded by the for Cardiac Surgery Foundation of the Free University of Brussels (B. El Oumeiri), the Saucez-Van Pouke Foundation (B. El Oumeiri, K. Mc Entee, and P. Van de Borne).

\section{Availability of data and materials}

All materials and data are available at request at the Laboratory of

Physiology of the University of Brussels.

\section{Authors' contributions}

BE carried out the experiments, performed the statistical analysis and drafted the manuscript and participated in the design of the study. KME coordinated the study and participated in its design.

FA and AH carried out the echocardiography. FVD participated in the coordination of the study. PJ did the technical assistance GVN performed the statistical analysis and reviewed the manuscript. PVB conceived the study and participated in the drafting of the manuscript. All authors read and approved the final manuscript.

\section{Ethics approval}

Experiments were approved by the Institutional Animal Care and Use Committee of the Free University of Brussels under $N^{\circ} 461 \mathrm{~N}$. Studies were conducted at the Laboratory of Physiology of the University of Brussels (LA 1230334) in accordance with the Guide for the Care and Use of Laboratory Animals published by the National Institutes of Health (NIH Publication No. 85-23, revised 1996).

\section{Competing interests}

The authors declare that they have no competing interests.

\section{Publisher's Note}

Springer Nature remains neutral with regard to jurisdictional claims in published maps and institutional affiliations.

\section{Author details}

'Department of Cardiac surgery, Erasme Hospital, ULB, 808 Lennik road, 1070, Brussels, Belgium. ${ }^{2}$ Laboratory of Physiology and Pharmacology, ULB, Brussels, Belgium. ${ }^{3}$ Department of intensive care, Erasme Hospital, ULB, Brussels, Belgium. ${ }^{4}$ Department of Cardiology, Erasme Hospital, ULB, Brussels, Belgium.

Received: 9 February 2017 Accepted: 7 May 2018

Published online: 21 May 2018

References

1. Maurer G. Aortic regurgitation. Heart. 2006 Jul;92(7):994-1000.

2. Dujardin KS, Enriquez-Sarano M, Schaff HV, Bailey KR, Seward JB, Tajik AJ. Mortality and morbidity of aortic regurgitation in clinical practice. A longterm follow-up study. Circulation. 1999 Apr 13;99(14):1851-7.

3. Chockalingam A, Gnanavelu G, Elangovan S, Chockalingam V. Current profile of acute rheumatic fever and valvulitis in southern India. J Heart Valve Dis. 2003 Sep;12(5):573-6.

4. Carabello BA. Aortic regurgitation. A lesion with similarities to both aortic stenosis and mitral regurgitation. Circulation. 1990 Sep;82(3):1051-3.

5. Bonow RO. Aortic Regurgitation. Curr Treat Options Cardiovasc Med. 2000 Apr;2(2):125-32.

6. Evangelista A, Tornos P, Sambola A, Permanyer-Miralda G, Soler-Soler J. Long-term vasodilator therapy in patients with severe aortic regurgitation. N Engl J Med. 2005 Sep 29:353(13):1342-9.

7. Mahajerin A, Gurm HS, Tsai TT, Chan PS, Nallamothu BK. Vasodilator therapy in patients with aortic insufficiency: a systematic review. Am Heart J. 2007 Apr;153(4):454-61.

8. Magid NM, Opio G, Wallerson DC, Young MS, Borer JS. Heart failure due to chronic experimental aortic regurgitation. Am J Physiol. 1994 Aug;267(2 Pt 2):H556-62.

9. Plante E, Couet J, Gaudreau M, Dumas MP, Drolet MC, Arsenault M. Left ventricular response to sustained volume overload from chronic aortic valve regurgitation in rats. J Card Fail. 2003 Apr;9(2):128-40.

10. Borer JS, Hochreiter C, Herrold EM, et al. Prediction of indications for valve replacement among asymptomatic or minimally symptomatic patients with chronic aortic regurgitation and normal left ventricular performance. Circulation. 1998;97:525-34. 
11. Borow KM. Surgical outcome in chronic aortic regurgitation: a physiologic framework for assessing preoperative predictors. J Am Coll Cardiol. 1987 Nov;10(5):1165-70.

12. Weber KT, Brilla CG. Pathological hypertrophy and cardiac interstitium. Fibrosis and renin-angiotensin-aldosterone system. Circulation. 1991 Jun;83(6):1849-65.

13. Krum H, Teerlink JR. Medical therapy for chronic heart failure. Lancet. 2011 Aug 20;378(9792):713-21.

14. Psotka MA, Teerlink JR. Direct myosin activation by Omecamtiv Mecarbil for heart failure with reduced ejection fraction. Handb Exp Pharmacol. 2017; 243:465-90.

15. Shen YT, Malik Fl, Zhao X, Depre C, Dhar SK, Abarzúa P, Morgans DJ, Vatner SF. Improvement of cardiac function by a cardiac myosin activator in conscious dogs with systolic heart failure. Circ Heart Fail. 2010 Jul;3(4):522-7.

16. Malik FI, Hartman JJ, Elias KA, Morgan BP, Rodriguez H, Brejc K, et al. Cardiac myosin activation: a potential therapeutic approach for systolic heart failure. Science. 2011 Mar 18;331(6023):1439-43.

17. Umana E, Solares CA, Alpert MA. Tachycardia-induced cardiomyopathy. Am J Med. 2003 Jan;114(1):51-5.

18. Arsenault M, Plante E, Drolet MC, Couet J. Experimental aortic regurgitation in rats under echocardiographic guidance. J Heart Valve Dis. 2002 Jan;11(1): 128-34.

19. Zoghbi WA, Enriquez-Sarano M, Foster E, Grayburn PA, Kraft CD, Levine RA, et al. Recommendations for evaluation of the severity of native valvular regurgitation with two-dimensional and Doppler echocardiography. J Am Soc Echocardiogr. 2003 Jul;16(7):777-802.

20. Lewis RP, Rittogers SE, Froester WF, Boudoulas H. A critical review of the systolic time intervals. Circulation. 1977 Aug;56(2):146-58.

21. Spodick DH, Doi YL, Bishop RL, Hashimoto T. Systolic time intervals reconsidered. Reevaluation of the preejection period: absence of relation to heart rate. Am J Cardiol. 1984 Jun 1;53(11):1667-70.

22. Stevenson LW. Clinical use of inotropic therapy for heart failure: looking backward or forward? Part II: chronic inotropic therapy. Circulation. 2003 Jul 29;108(4):492-7.

23. Wisenbaugh T, Allen P, Cooper G 4th, O'Connor WN, Mezaros L, Streter F, Bahinski A, Houser S, Spann JF. Hypertrophy without contractile dysfunction after reversal of pressure overload in the cat. Am J Phys. 1984 Jul;247(1 Pt 2): H146-54.

24. Bekeredjian R, Grayburn PA. Valvular heart disease: aortic regurgitation. Circulation. 2005 Jul 5;112(1):125-34.

25. Boudoulas H. Systolic time intervals. Eur Heart J. 1990 Dec;11 Suppl 1:93-104

26. Teerlink JR, Felker GM, McMurray JJ, Solomon SD, Adams KF Jr, Cleland JG, Ezekowitz JA, Goudev A, Macdonald P, Metra M, Mitrovic V, Ponikowski P, Serpytis P, Spinar J, Tomcsányi J, Vandekerckhove HJ, Voors AA, Monsalvo ML, Johnston J, Malik Fl. Honarpour N; COSMIC-HF investigators. Chronic oral study of myosin activation to increase contractility in heart failure (COSMIC-HF): a phase 2, pharmacokinetic, randomised, placebo-controlled trial. Lancet. 2016 Dec 10:388(10062):2895-903.

27. Wallace AG, Mitchell JH, Skinner NS, Sarnoff SJ. Duration of the phases of left ventricular systole. Circ Res. 1963 Jun;12:611-9.

28. Greenberg BH, Chou W, Saikali KG, Escandón R, Lee JH, Chen MM, Treshkur T, Megreladze I, Wasserman SM, Eisenberg P, Malik FI, Wolff AA, Shaburishvili T. Safety and tolerability of omecamtiv mecarbil during exercise in patients with ischemic cardiomyopathy and angina. JACC Heart Fail. 2015 Jan;3(1):22-9.

29. Petersen JW, Felker GM. Inotropes in the management of acute heart failure. Crit Care Med. 2008 Jan;36(1 Suppl):S106-11.

30. Espinola-Zavaleta N, Gómez-Núñez N, Chávez PY, Sahagun-Sánchez G, Keirns C, Casanova JM, Romero-Cárdenas A, Roldán FJ, Vargas-Barrón J. Evaluation of the response to pharmacological stress in chronic aortic regurgitation. Echocardiography. 2001 Aug;18(6):491-6.

31. Levänen J, Mäkelä ML, Scheinin H. Dexmedetomidine premedication attenuates ketamine-induced cardio-stimulatory effects and post-anesthetic delirium. Anesthesiology. 1995 May;82(5):1117-25.

32. Lee K, Hwang HJ, Kim OS, Oh YJ. Assessment of dexmedetomidine effects on left ventricular function using pressure-volume loops in rats. J Anesth. 2017 Feb;31(1):18-24.

33. Asai $K$, Uechi M, Sato N, Shen W, Meguro T, Mathier MA, Shannon RP, Vatner SF. Lack of desensitization and enhanced efficiency of calcium channel promoter in conscious dogs with heart failure. Am J Phys. 1998 Dec;275(6 Pt 2):H2219-26.

34. Banfor PN, Preusser LC, Campbell TJ, Marsh KC, Polakowski JS, Reinhart GA Cox BF, Fryer RM. Comparative effects of levosimendan, OR-1896, OR-1855, dobutamine, and milrinone on vascular resistance, indexes of cardiac function, and $\mathrm{O} 2$ consumption in dogs. Am J Physiol Heart Circ Physiol. 2008 Jan;294(1):H238-48.

35. Anderson RL, Sueoka SH, Lee KH, Rodriguez HM, Kawas RF, Godinez G, Morgan BP, Sakowicz R, Morgans DJ, Malik F, Elias KA. In vitro and in vivo characterization of CK-1827452, a selective cardiac myosin activator. J Card Fail. 2006;12:586

36. Teerlink JR, Clarke CP, Saikali KG, Lee JH, Chen MM, Escandon RD, Elliott L, Bee R, Habibzadeh MR, Goldman JH, Schiller NB, Malik FI, Wolff AA. Dosedependent augmentation of cardiac systolic function with the selective cardiac myosin activator, omecamtiv mecarbil: a first-in-man study. Lancet. 2011 Aug 20;378(9792):667-75

37. Tariq S, Aronow WS. Use of inotropic agents in treatment of systolic heart failure. Int J Mol Sci. 2015 Dec 4;16(12):29060-8.

38. Kojima S, Wu ST, Parmley WW, Wikman-Coffelt J. Relationship between intracellular calcium and oxygen consumption: effects of perfusion pressure, extracellular calcium, dobutamine, and nifedipine. Am Heart J. 1994 Feb; 127(2):386-91.

39. Tsien RW, Bean BP, Hess P, Lansman JB, Nilius B, Nowycky MC. Mechanisms of calcium channel modulation by beta-adrenergic agents and dihydropyridine calcium agonists. J Mol Cell Cardiol. 1986 Jul;18(7):691-710.

40. \Hasenfuss G, Pieske B, Castell M, Kretschmann B, Maier LS, Just H. Influence of the novel inotropic agent levosimendan on isometric tension and calcium cycling in failing human myocardium. Circulation. 1998 Nov 17:98(20):2141-7.

41. Moin DS, Sackheim J, Hamo CE, Butler J. Cardiac Myosin Activators in Systolic Heart Failure: More Friend than Foe? Curr Cardiol Rep. 2016 Oct;18(10):100.

42. Bakkehaug JP, Kildal AB, Engstad ET, Boardman N, Næsheim T, Rønning L, Aasum E, Larsen TS, Myrmel T, How OJ. Myosin Activator Omecamtiv Mecarbil Increases Myocardial Oxygen Consumption and Impairs Cardiac Efficiency Mediated by Resting Myosin ATPase Activity. Circ Heart Fail. 2015 Jul:8(4):766-75.

43. Teerlink JR, Malik FI, Kass DA. Letter by Teerlink et al regarding article, "myosin activator Omecamtiv Mecarbil increases myocardial oxygen consumption and impairs cardiac efficiency mediated by resting myosin ATPase activity". Circ Heart Fail. 2015 Nov;8(6):1141.

44. Anderson RL, Sueoka SH, Rodriguez HM, Lee KH, Cox DR, Kawas R, Morgan BP, Sakowicz R, Morgans DJ, Malik F, Elias KA. In vitro and in vivo efficacy of the cardiac myosin activator CK-1827452. Mol bio cell. 2005;16(abstract \#1728). https://cytokinetics.com/wp-content/uploads/2015/10/ASCB_1728.pdf.

45. Cleland JG, Teerlink JR, Senior R, Nifontov EM, MC Murray JJ, Lang CC, et al. The effects of the cardiac myosin activator, omecamtiv mecarbil, on cardiac function in systolic heart failure: a double-blind, placebo-controlled, crossover, dose-ranging phase 2 trial. Lancet. 2011 Aug 20;378(9792):676-83.

46. Teerlink JR, Felker GM, McMurray JJ, Ponikowski P, Metra M, Filippatos GS. ATOMIC-AHF investigators. Acute treatment with Omecamtiv Mecarbil to increase contractility in acute heart failure: the ATOMIC-AHF study. J Am Coll Cardiol. 2016 Mar 29;67(12):1444-55.

47. Nánási P Jr, Gaburjakova M, Gaburjakova J, Almássy J. Omecamtiv mecarbil activates ryanodine receptors from canine cardiac but not skeletal muscle. Eur J Pharmacol. 2017 Aug 15:809:73-9.

48. Dervan J, Goldberg S. Acute aortic regurgitation: pathophysiology and management. Cardiovasc Clin. 1986;16(2):281-8.

\section{Ready to submit your research? Choose BMC and benefit from:}

- fast, convenient online submission

- thorough peer review by experienced researchers in your field

- rapid publication on acceptance

- support for research data, including large and complex data types

- gold Open Access which fosters wider collaboration and increased citations

- maximum visibility for your research: over $100 \mathrm{M}$ website views per year

At BMC, research is always in progress.

Learn more biomedcentral.com/submissions 